GASTRO-OESOPHAGEAL REFLUX

\title{
Weakly acidic reflux in patients with chronic unexplained cough during 24 hour pressure, $\mathrm{pH}$, and impedance monitoring
}

\author{
D Sifrim, L Dupont, K Blondeau, X Zhang, J Tack, J Janssens
}

Gut 2005;54:449-454. doi: 10.1136/gut.2004.055418

See end of article for authors' affiliations

Correspondence to:

Correspondence to:
Professor D Sifrim, Faculty of Medicine, KU Leuven, Lab G-I Physiopathology,

O\&N Gasthuisberg, 7 th

floor, Herestraat 49, 3000,

Leuven, Belgium;

Daniel.Sifrim@

med.kuleuven.ac.be

Revised version received 4 October 2004 Accepted for publication 12 October 2004
Background and aims: Acid gastro-oesophageal reflux is one of the most important causes of chronic cough. The response to acid suppression in these patients is not as good as in patients with heartburn but improvement with antireflux surgery has been reported, suggesting the involvement of a non-acidic gastric component in the refluxate. Less acidic reflux may produce symptoms such as regurgitation or chest pain. We investigated whether chronic cough might be associated with weakly acidic reflux.

Methods: We studied 28 patients with chronic cough using 24 hour ambulatory pressure-pH-impedance monitoring. Manometry was used for precise recognition of cough and impedance-pHmetry to detect acid $(\mathrm{pH}<4)$, weakly acidic ( $\mathrm{pH} 7-4)$, and weakly alkaline (impedance drops, $\mathrm{pH} \geqslant 7$ ) reflux. A symptom association probability (SAP) analysis was performed for each type of reflux.

Results: Analysis was completed in 22 patients with 24 cough events (5-92)/patient. The majority of cough events (69.4\%) were considered "independent" of reflux whereas $30.6 \%$ occurred within two minutes of a reflux episode. Half of these (49\%) were "reflux cough" sequences, involving acid (65\%), weakly acidic (29\%), and weakly alkaline (6\%) reflux. Ten patients $(45 \%)$ had a positive SAP between reflux and cough: five with acid, two with acid and weakly acidic, and three only with weakly acidic reflux. Conclusions: Ambulatory pressure-pH-impedance monitoring with SAP analysis allowed precise determination of the temporal association between cough and gastro-oesophageal reflux (acid, weakly acidic, and weakly alkaline) and identification of a subgroup of patients with chronic cough clearly associated with weakly acidic gastro-oesophageal reflux.
$\mathrm{P}$ ersistent cough for more than eight weeks is a common problem, which frequently results in significant limitation of daily activities and quality of life. ${ }^{1}$ Acid gastrooesophageal reflux has been identified as one of the most important causes of chronic cough. ${ }^{2}$

Accurate diagnosis of chronic cough due to reflux is a major challenge. Prospective studies, in which the underlying cause of the chronic cough was determined in the majority of patients, showed that the positive and negative predictive value of reflux indexes derived from oesophageal $\mathrm{pH}$ monitoring were $89 \%$ and $100 \%$, respectively. ${ }^{3}{ }^{4}$ In contrast, Ours et al reported that only $35 \%$ of patients with chronic cough and an abnormal pH profile responded favourably to proton pump inhibitor therapy. ${ }^{5}$ A number of reasons may account for this observed discrepancy, including treatment duration, resistance to acid suppression, or triggering of cough by a non-acidic component of the gastro-oesophageal refluxate. For example, symptoms such as heartburn, regurgitation, or non-cardiac chest pain may be induced by less acidic or gas reflux that is not detected by pHmetry. ${ }^{6-8}$

Oesophageal pH monitoring does not detect all gastrooesophageal reflux events, particularly when little or no acid is present in the refluxate. This is the case in both adults and infants after eating, before the gastric contents have become acidified, and it also applies to reflux in patients undergoing antisecretory therapy. Oesophageal impedance monitoring is a new method that can achieve the highest sensitivity for detection of reflux episodes. ${ }^{9-11}$ Combined oesophageal impedance with pHmetry allows detection and classification of all reflux events into acid, weakly acidic, and weakly alkaline reflux. $^{12}$

In suspected patients, it is important to determine a causal relation between reflux and cough. Although imperfect, a close and consistent temporal association would be suggestive of causality. Whether cough is induced by or provokes reflux should be clarified to establish the appropriate treatment. To date, studies investigating the relation between reflux and cough either did not consider less acidic reflux events or used event markers and diary annotations to identify cough. ${ }^{4{ }^{13-17}}$ This is likely to have underestimated the number of reflux and cough events and may also have been unreliable in determining their time association.

We hypothesised that an objective marker of cough and detection of all type of reflux by impedance-pH monitoring would help to better characterise the role of gastrooesophageal reflux in the pathogenesis of chronic cough.

The aims of this study were: (1) to determine the precise temporal association between cough and different types of gastro-oesophageal reflux (acid, weakly acidic, and weakly alkaline) and (2) to identify a subgroup of patients with chronic cough associated with less acidic gastro-oesophageal reflux.

\section{METHODS}

\section{Subjects}

Simultaneous 24 hour ambulatory oesophageal pressure, $\mathrm{pH}$, and impedance monitoring were performed in 28 consecutive patients with chronic cough ( 11 men; median age 56 years (range 42-81)). Patients were selected by the Pneumology Department, Gasthuisberg University Hospital KU Leuven, because of daily cough of unclear aetiology for at least eight weeks. Before reflux testing, other causes of chronic cough were excluded. All patients were immunocompetent, had a

Abbreviations: SAP, symptom association probability; GORD, gastrooesophageal reflux disease; LOS, lower oesophageal sphincter 


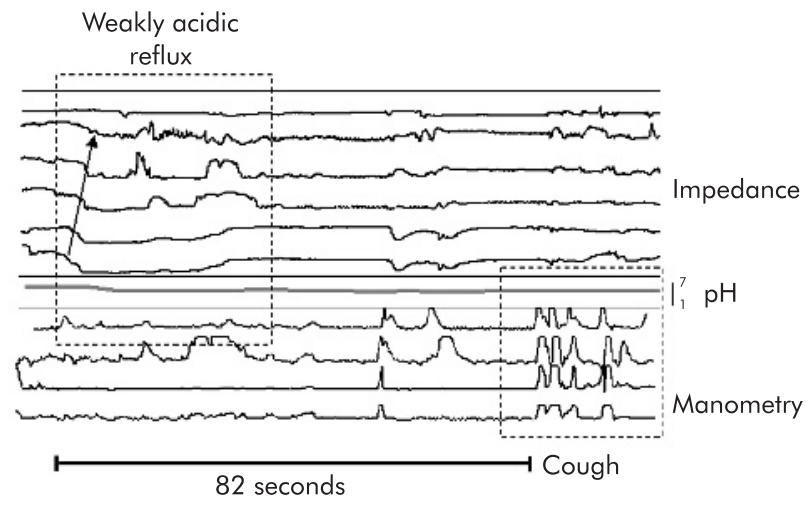

Figure 1 Tracings of concurrent oesophageal manometry, $\mathrm{pH}$, and impedance. Example of a "reflux cough" sequence. The impedance tracing shows a retrogradely propagated drop consistent with liquid reflux, and the oesophageal pH fell more than $1 \mathrm{pH}$ unit but remained above 4 (weakly acidic reflux). The manometric tracing shows a cough burst consisting of phasic, short duration, rapid pressure rises occurring simultaneously and with the same pressure configuration at all manometric recording sites. Cough occurred 82 seconds after the start of a weakly acidic reflux event.

normal chest $x$ ray, and none used angiotensin converting enzyme inhibitors. Asthma was excluded by negative histamine provocative tests, normal sputum eosinophilia, and absence of improvement with antiasthmatic medication. Postnasal drip syndrome was excluded both clinically and by negative sinus imaging. None of the patients had undergone previous gastrointestinal surgery or were taking medications known to influence oesophageal function. A standardised questionnaire was used to obtain a history of each patient regarding typical and atypical symptoms of gastro-oesophageal reflux disease (GORD). If patients were receiving empirical antireflux therapy, acid suppression medication was stopped at least two weeks before the measurements. During the impedance-pH study day, patients were asked to stop or reduce their antitussive medication. The study was approved by the University Hospital ethics committee and written informed consent was obtained from all subjects.

\section{Recording equipment and technique}

Cough and gastro-oesophageal reflux were monitored simultaneously using two synchronised ambulatory systems. Cough was assessed using gastro-oesophageal manometry whereas reflux was detected by oesophageal pH-impedance.

A manometric catheter with four solid-state pressure sensors (Unisensor AG, Attikon, Switzerland) was passed transnasally. A slow pull through technique was used to locate the proximal margin of the lower oesophageal sphincter (LOS). The catheter was positioned so as to record pressures in the stomach, LOS, and at 5 and $10 \mathrm{~cm}$ proximal to the LOS in the oesophageal body. The pressure measurements were recorded in a portable data logger (MMS, UPS2020, Enschede, the Netherlands) that sampled and stored the digitised data at $4 \mathrm{~Hz}$ per channel.

Oesophageal pH-impedance was recorded with a $2.1 \mathrm{~mm}$ diameter catheter that comprised six impedance electrode pairs and one antimony pH sensor (Sandhill Scientific Inc., Highlands Ranch, Colorado, USA). An impedance amplifier delivered ultra low current in the range $1-2 \mathrm{kHz}$ with resulting current flow variations in response to intraluminal impedance changes. The signals from the impedance and $\mathrm{pH}$ channels were digitised at $50 \mathrm{~Hz}$ and stored in a separate data logger (Sandhill Scientific Inc.). Before the start of the recording, the $\mathrm{pH}$ electrode was calibrated using $\mathrm{pH} 4.0$ and pH 7.0 buffer solutions.

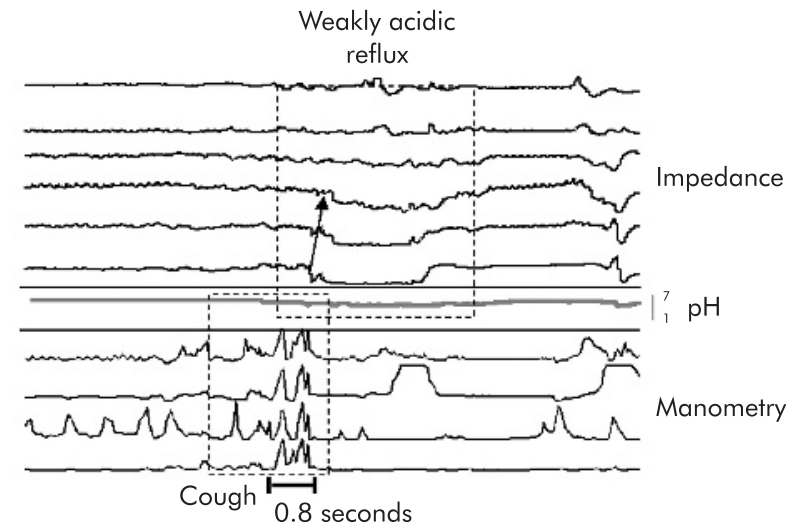

Figure 2 Tracings of concurrent oesophageal manometry, $\mathrm{pH}$, and impedance. Example of a "cough-reflux" sequence. The manometric tracing shows a cough burst consisting of phasic, short duration, rapid pressure rises occurring simultaneously and with the same pressure configuration at all manometric recording sites. The impedance tracing shows a retrogradely propagated drop consistent with liquid reflux and the oesophageal $\mathrm{pH}$ fell more than $1 \mathrm{pH}$ unit but remained above 4 (weakly acidic reflux). Weakly acidic reflux occurred 0.8 seconds after the start of a cough burst.

\section{Study protocol}

The study was performed on an outpatient basis after an overnight fast. The manometric and $\mathrm{pH}$-impedance catheters were passed transnasally under topical anaesthesia and positioned to record $\mathrm{pH}$ at $5 \mathrm{~cm}$ and impedance at 3, 5, 7, 9,15 , and $17 \mathrm{~cm}$ proximal to the LOS in the oesophageal body. Patients were encouraged to maintain normal activities, sleep schedule, and eat their usual meals at their normal times. Event markers on the $\mathrm{pH}$-impedance data logger recorded meal times and posture changes. Before the study, patients were instructed to keep a careful diary and trained to use the event marker in the data logger to record cough episodes and other events.

\section{Data analysis}

The manometric and $\mathrm{pH}$-impedance recordings were uploaded onto a personal computer, synchronised, and displayed on a single screen for computer assisted manual analysis (Review, A Andrioli, KU Leuven, Belgium).

\section{Cough detection}

The manometric tracing was independently analysed for cough episodes. Cough was defined according to Paterson and Murat as phasic, short duration, rapid pressure rises (time to peak $<1$ second) occurring simultaneously and with the same pressure configuration at all manometric recording sites. ${ }^{16}$ A "cough burst" was defined as two or more rapid simultaneous pressure peaks within three seconds (fig 1). Only "cough bursts" were considered in the further analysis and patients with less than five cough bursts in 24 hours were excluded.

\section{Reflux detection}

The $\mathrm{pH}$-impedance recordings were independently analysed for gastro-oesophageal reflux. Gastro-oesophageal reflux was defined as a sequential orally progressing drop in impedance to less than $50 \%$ of baseline values starting distally $(3 \mathrm{~cm}$ above the LOS) and propagating retrogradely to at least the next two more proximal measuring segments. According to the corresponding $\mathrm{pH}$ change, impedance detected reflux was classified as acid if $\mathrm{pH}$ fell below 4 for at least four seconds or, if $\mathrm{pH}$ was already below 4, as a decrease of at least $1 \mathrm{pH}$ unit sustained for more than four seconds. Weakly acidic reflux 
was defined as a pH drop of at least $1 \mathrm{pH}$ unit sustained for more than four seconds with basal $\mathrm{pH}$ remaining between 7 and 4. Reflux was judged to be weakly alkaline when there was impedance evidence of reflux but the $\mathrm{pH}$ did not drop below $7 .^{12}$

For each reflux episode, as determined by pH-impedance, the associated gas-liquid pattern was classified as: (i) mixed reflux of liquid and gas or (ii) liquid reflux. Only gas reflux episodes (belches) were not included in the analysis. The proximal extent of each reflux event was evaluated from the impedance tracings. For each patient, the total number of reflux events (acid, weakly acidic, and weakly alkaline), acid exposure time at $5 \mathrm{~cm}$ above the LOS, and average proximal extent of reflux were calculated.

\section{Association between reflux and cough}

A two minute period preceding and following the onset of a reflux episode was chosen to delimitate the time window for association between cough and reflux. ${ }^{18}$ Cough that fell outside the two minute time window around a reflux episode was considered to have occurred "independent" of reflux. We defined a cough as being "induced" by reflux ("refluxcough") if the cough occurred within two minutes after the onset of the reflux episode (fig 1). We defined a cough as "precipitating" reflux ("cough-reflux") if the reflux event occurred within two minutes immediately following a cough (fig 2).

We first considered all cough bursts in all subjects (pooled data) and calculated the proportion of cough bursts "independent", "induced by", or "precipitating" reflux in the patients group. In a second step, we performed a per individual analysis and calculated the symptom association probability (SAP). ${ }^{19}$ SAP values greater than 95\% were considered statistically significant. Automated calculation of SAP for all impedance detected reflux and for acid, weakly acidic, and weakly alkaline reflux separately was performed using dedicated software (Dr Radu Tutuian, Medical University of South Carolina, USA).

\section{Statistical analysis}

Data are presented as median (range) unless otherwise stated. The paired Student's $t$ test was used for comparison of the proximal extent of reflux. Fisher's exact test was used to

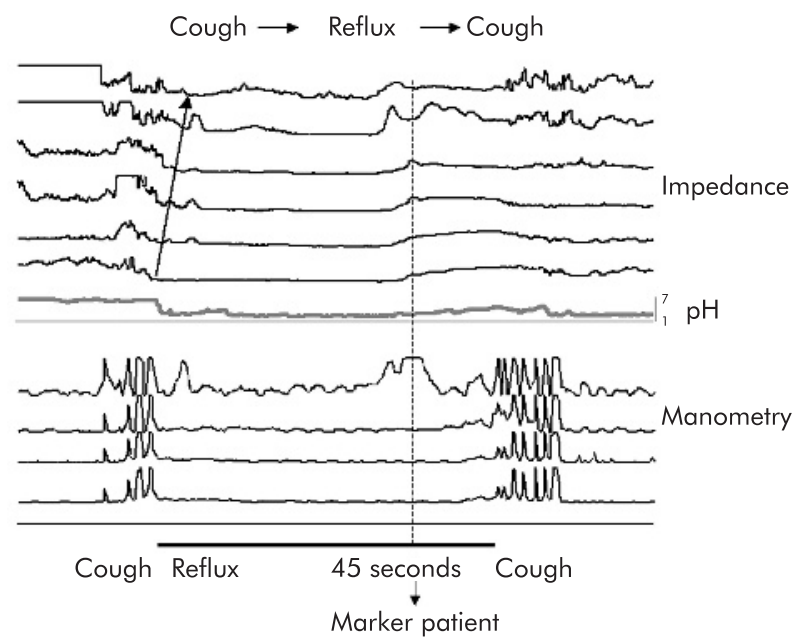

Figure 3 Tracings of concurrent oesophageal manometry, $\mathrm{pH}$, and impedance. Example of a "cough-reflux-cough" sequence. The patient used the event marker in the data logger after an acid reflux event, suggesting a "reflux-cough" episode. However, manometry showed a previous cough event that precipitated acid reflux. calculate SAP. Statistical significance was accepted when $\mathrm{p}<0.05$.

\section{RESULTS}

A total of 28 patients with chronic cough were selected. Six patients were excluded: two because of continuous intake of proton pump inhibitors; one due to technical problems in the pH-impedance recording; and three patients did not have more than five cough bursts during the study day.

Analysis was therefore completed in 22 patients (eight men; median age 55 (43-81) years).

\section{Cough}

A total of 647 cough bursts (24 (5-92)/patient) were analysed of which 105 occurred during the night. Three patients coughed only during the day but the majority of patients had both day and night time cough bursts.

The number of manometrically detected cough bursts (647) was significantly higher than the number of cough episodes indicated by patients using the event marker in the data logger and/or the diary (that is, only 39\% (21-56) of cough bursts detected manometrically were marked by the patients).

When the event marker was used, the delay between the start of coughing detected by manometry and the symptom marked by the patient was $28(7-80)$ seconds.

\section{Gastro-oesophageal reflux}

Eight patients had typical GORD symptoms (pyrosis and/or regurgitation). Hoarseness was present as a secondary symptom in eight patients, and dysphagia and exaggerated belching in another three patients. There was no significant difference in the number of cough bursts between patients with and without GORD symptoms during the study day.

Ten patients had abnormal distal oesophageal acid exposure $(6.8 \%(1.10-19.8 \%))$. Distal acid exposure was $8.2 \%$ in patients with GORD symptoms and $5.2 \%$ in patients without (NS). Four patients with chronic cough without GORD symptoms had abnormal acid exposure.

A total number of 966 gastro-oesophageal reflux events (39.5 (11-89)/patient) were detected by impedance and were classified by $\mathrm{pH}$ as acid reflux $(\mathrm{n}=575)(22.5 \quad(0-65) /$ patient)), weakly acidic reflux $(\mathrm{n}=328)(13(3-37) /$ patient $)$, and weakly alkaline reflux $(\mathrm{n}=63)(0.5(0-16) /$ patient $)$.

\section{Association between reflux and cough}

From the total number of cough bursts analysed (pooled data), the majority $(449 / 647(69.4 \%))$ were considered "independent" of reflux whereas 198/647 (30.6\%) occurred within the two minute time window around a reflux episode. Half of these episodes (49\%) were preceded by reflux (refluxcough) and the other half were followed by reflux (coughreflux). From 98 reflux-cough episodes, 65\% involved acid reflux, 29\% involved weakly acidic reflux, and $6 \%$ involved weakly alkaline reflux.

From the total number of reflux events analysed (pooled data), 203/966 (21\%) were time associated with cough. In the reflux-cough episodes, the median time between the start of reflux and cough was 44 seconds (41-51) whereas in the cough-reflux episodes, the median time between cough and reflux was 40 seconds (39-54).

On several occasions, patients used the event marker in the data logger after a reflux event, suggesting a reflux-cough episode during the independent reflux analysis. However, manometry unmasked a previous cough event that precipitated reflux. We found the sequence cough-reflux-cough in nine patients (1 (1-7)/patient), being particularly frequent in one patient (fig 3). 
In 16 patients, SAP analysis was positive for impedance detected reflux. These patients had a statistically significant number of two minute intervals containing both reflux and symptoms $\left(\mathrm{R}^{+} \mathrm{S}^{+}\right)$. In all patients we found "reflux-cough" and "cough-reflux" sequences. Ten SAP positive patients had predominantly (more than $50 \%$ of $\left(\mathrm{R}^{+} \mathrm{S}^{+}\right)$intervals) the sequence "reflux-cough" and were considered to have cough "induced by" reflux. SAP was positive for any reflux detected by impedance in nine patients, only for acid reflux in five patients, only for weakly acidic reflux in three patients, and for both acid and weakly acidic reflux in two patients. There was no patient with SAP positive for weakly alkaline reflux (fig 4).

In the 10 patients with SAP positive with cough "induced by" reflux, we compared the characteristics of the reflux episodes associated and not associated with cough. There was no significant difference in mean $\mathrm{pH}(3.6 \vee 3.9)$, proximal extent in centimetres above the LOS $(9.8 v 9.3)$, or presence of gas in the refluxate $(63 \% v 66 \%)$.

Six SAP positive patients had predominantly (more than $50 \%$ of $\left(\mathrm{R}^{+} \mathrm{S}^{+}\right)$intervals) the sequence "cough-reflux" and were considered to have cough "precipitating" reflux.

\section{Gain of manometry-pH-impedance and SAP analysis versus GORD symptoms and pHmetry}

From the 22 patients included, 13 had abnormal pHmetry and/or typical GORD symptoms. Three of these patients had SAP negative for any type of reflux and could be considered "false positives". In four of the nine patients without GORD symptoms and normal pHmetry, SAP was positive and could be considered "false negatives". Therefore, the use of manometry-pH-impedance with SAP analysis modified the diagnosis in $7 / 22$ patients.

Three of the four patients considered "false negative" for pHmetry and GORD symptoms had SAP positive with predominant "reflux-cough" sequences involving weakly acidic reflux.

\section{DISCUSSION}

Acid reflux is considered a frequent cause of chronic cough, and oesophageal instillation of acid solutions may increase symptoms in selected patients with cough and abnormal pHmetry. ${ }^{20}$ Less acidic reflux ( $\left.\mathrm{pH} 4-7\right)$ may also induce symptoms of GORD, such as heartburn, regurgitation, and

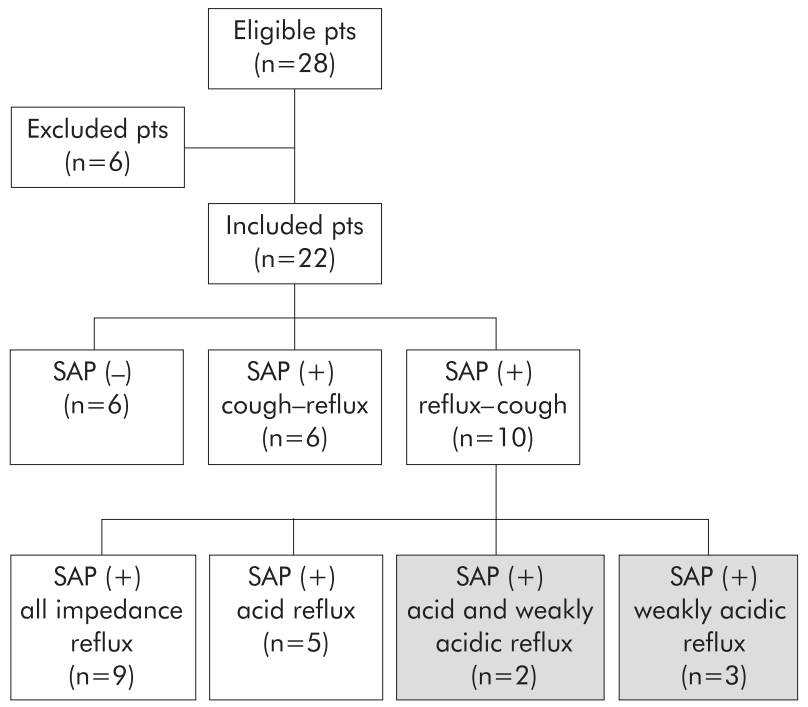

Figure 4 Flow diagram of the study population. Per individual symptom association analysis (SAP) was performed. Five patients had SAP positive for weakly acidic reflux (shaded boxes). non-cardiac chest pain. ${ }^{6-8}$ In the present study, we assessed the precise temporal relation between cough, objectively detected by manometry, and reflux of different degrees of acidity, diagnosed by impedance-pHmetry. Using this diagnostic approach, we identified a subgroup of patients with chronic cough clearly associated with weakly acidic gastrooesophageal reflux.

Precise temporal identification of both cough and reflux is mandatory to certify their association. Our study approached this problem using state of the art methodology (that is, manometry to detect cough, impedance-pH to detect reflux, and SAP analysis to quantify the probability of chance association).

Although there is no gold standard for diagnosis of reflux related cough, 24 hour pHmetry and cough recording using event markers has been the method most frequently used. ${ }^{4}{ }^{13-17}$ During conventional analysis of 24 hour pHmetry, detection of reflux is restricted to $\mathrm{pH}$ drops to below 4, with less acidic reflux events disregarded. However, from the total number of reflux episodes detected by $\mathrm{pH}-$ impedance in our study, $40 \%$ were weakly acidic and weakly alkaline.

Using concurrent oesophageal manometry and pHmetry, Paterson and Murat showed that the use of a diary or event marker for determination of cough is inadequate because patients underestimate the frequency of cough events or misreport their timing. ${ }^{16}$ In our study, patients indicated, with a delay of around 30 seconds, only $40 \%$ of cough bursts detected manometrically.

A positive SAP indicates that the observed association between reflux and symptoms is not caused by chance. ${ }^{19}$ Wunderlich and Murray first used SAP analysis to determine the temporal relationship between cough and acid reflux and found that $35 \%$ of patients had a positive SAP. ${ }^{17}$ Recent studies using 48 hour wireless pHmetry showed a significant gain in the likelihood of establishing a relationship between chest pain and reflux by duplicating the number of pain events detected. ${ }^{21}$ Using pressure-pH-impedance monitoring, we detected almost double the number of reflux and cough episodes per subject that could have been identified by pHmetry and cough markers. In our study, 16 patients had a positive SAP $(72 \%)$ and $10(45 \%)$ had predominant refluxcough sequences.

Although SAP analysis seems to be the most appropriate method, to date, to characterise the association between reflux and symptoms still requires adaptation to different symptoms and further validation. A positive SAP that relates cough to reflux episodes needs to be prospectively validated against an independent criterion of diagnostic accuracy such as prediction of symptomatic response to antireflux therapy.

The percentage of patients with chronic cough ascribed to acid reflux ranges from $10 \%$ to $90 \% .^{3}{ }^{13}{ }^{14} 2-24$ In our patients, acid reflux was very common. Abnormal distal oesophageal acid exposure was found in 10 patients and seven patients had positive SAP for acid reflux.

After acid reflux, weakly acidic reflux represented almost $40 \%$ of reflux episodes. Moreover, we identified five patients $(23 \%)$ where the SAP was positive for weakly acidic reflux. Weakly alkaline reflux was very rare and there was no patient with a positive SAP for this type of refluxate. Although less acidic reflux episodes have been recognised for many years, they were neglected and their real prevalence and clinical relevance remained under investigated. However, previous studies have indirectly suggested that in addition to acid, other gastric content components might be relevant in chronic cough. In two placebo controlled trials using proton pump inhibitors for gastro-oesophageal reflux related cough, ${ }^{52}$ a subgroup of patients did not respond to intense treatment. Some of these refractory patients improved their 
cough after antireflux surgery ${ }^{26}{ }^{27}$ suggesting that components of the refluxate, other than acid, could have played a role in their symptoms.

Six of our patients had predominantly "cough-reflux" sequences and were considered to have cough "precipitating" reflux. The use of manometry helped to identify the sequence cough-reflux-cough in nine patients and confirmed previous descriptions by Ing et al suggesting that a self perpetuating mechanism may exist whereby acid reflux causes cough and cough in turn amplifies reflux via increased transdiaphragmatic pressure or by inducing transient lower oesophageal sphincter relaxation. ${ }^{24} 28$

Neither the presence of typical reflux symptoms nor the characteristics of the cough are very good predictors of a positive association between them. ${ }^{29}$ Moreover, Irwin et al showed that $75 \%$ of patients with reflux related cough had no reflux symptoms. ${ }^{30}$ In our study, 10 of the patients included had typical reflux symptoms. However, from the 10 patients with positive SAP and "reflux induced" cough, six had no reflux symptoms.

On the other hand, these patients did not have a distinct pattern of cough (frequency, diurnal-nocturnal distribution, type of sputum production) compared with patients with chronic cough without reflux. It is commonly believed that nocturnal cough is typical of GORD but nocturnal episodes of coughing have been found to occur in patients with GORD as frequently as in those with other common causes of chronic cough. ${ }^{29}$ In our study, both supine reflux and nocturnal cough were infrequent.

The mechanism by which reflux causes cough is not yet clear but two important hypothesis have been suggested: firstly, micro-or macro-aspiration of refluxate into the larynx and tracheobronchial tree, and secondly, a vagally mediated oesophageal-tracheobronchial cough reflex..$^{24}$ In favour of the aspiration theory, multiple $\mathrm{pH}$ measurements showed some degree of correlation between proximal acid reflux and cough. ${ }^{3132}$ In our study, no difference was observed in proximal extent, mean $\mathrm{pH}$, or presence of gas in the refluxate between reflux episodes associated and not associated with cough.

The fact that weakly acidic reflux could be temporally related to cough suggests that the acidity of the refluxate might not be the only factor involved in this association. Distal oesophageal distension may induce symptoms such as heartburn or chest pain. ${ }^{33}{ }^{34}$ Similarly, oesophageal distension by spontaneous reflux may play a role in the reflex underlying gastro-oesophageal reflux-cough.

Our findings may have diagnostic and therapeutic implications. From the 22 patients included, 13 had abnormal pHmetry and/or typical GORD symptoms. Using manometry$\mathrm{pH}$-impedance and SAP analysis, we found no association between reflux and cough in three of these patients. Moreover, in four of the nine patients without GORD symptoms and normal pHmetry, SAP was positive mainly for weakly acidic reflux. Therefore, we were able to modify the diagnosis in $7 / 22$ patients. Furthermore, when treating patients with chronic cough and increased oesophageal acid exposure, precise temporal identification of cough and reflux will allow a distinction between patients with cough induced by reflux that deserve antireflux therapy from those where cough provokes reflux requiring treatment of the underlying respiratory condition with antitussive therapy.

The response in patients with reflux related cough to acid suppression with proton pump inhibitors is not as good as in patients with typical GORD symptoms. ${ }^{35}$ Refractory patients to aggressive proton pump inhibitor treatment can now be studied with manometry-impedance-pHmetry and SAP analysis. If a positive association between cough and weakly acidic reflux is found, these patients may benefit from reduction of gastro-oesophageal reflux during transient LOS relaxations, the main mechanism for both acid and weakly acidic reflux. ${ }^{36}$ This can be achieved either pharmacologically with the GABA agonist baclofen ${ }^{37}$ or with endoscopic or surgical antireflux procedures.

In summary, using ambulatory 24 hour pressure-pHimpedance monitoring, we were able to determine the precise temporal association between cough and different types of gastro-oesophageal reflux (acid, weakly acidic, and weakly alkaline). Symptom association analysis allowed identification of a subgroup of patients with chronic cough associated with weakly acidic gastro-oesophageal reflux.

\section{ACKNOWLEDGEMENTS}

This work was supported by grants from the FWO and the "Geconcerteerde Onderzoeksactie" of the University of Leuven.

\section{Authors' affiliations}

D Sifrim, L Dupont, K Blondeau, X Zhang, J Tack, J Janssens, Centre for Gastroenterological Research KU Leuven and Department of Pneumology, Gasthuisberg University Hospital, KU Leuven, Belgium

Conflict of interest: None declared.

\section{REFERENCES}

1 Morice AH, Kastelik JA. Cough. 1: Chronic cough in adults, Thorax 2003;58:901-7.

2 Fontana GA, Pistolesi M. Cough. 3: chronic cough and gastro-oesophageal reflux, Thorax 2003;58:1092-5.

3 Irwin RS, Curley FJ, French CL. Chronic cough. The spectrum and frequency of causes, key components of the diagnostic evaluation, and outcome of specific therapy. Am Rev Respir Dis 1990;141:640-7.

4 Vaezi MF, Richter JE. Twenty-four-hour ambulatory esophageal pH monitoring in the diagnosis of acid reflux-related chronic cough. South Med J 1997;90:305-11.

5 Ours TM, Kavuru MS, Schilz RJ, et al. A prospective evaluation of esophageal testing and a double-blind, randomized study of omeprazole in a diagnostic and therapeutic algorithm for chronic cough. Am J Gastroenterol 1999:94:3131-8.

6 Dent J, Holloway RH, Toouli J, et al. Mechanisms of lower oesophageal sphincter incompetence in patients with symptomatic gastro-oesophageal reflux. Gut 1988;29:1020-8

7 Breumelhof R, Nadorp JH, Akkermans LM, ef al. Analysis of 24-hour esophageal pressure and $\mathrm{pH}$ data in unselected patients with noncardiac chest pain. Gastroenterology 1990;99:1257-64.

8 Mattioli S, Pilotti V, Felice V, et al. Ambulatory 24-hr pH monitoring of esophagus, fundus, and antrum. A new technique for simultaneous study of gastro-oesophageal and duodenogastric reflux. Dig Dis Sci 1990;35:929-38.

9 Silny J. Intraluminal multiple electrical impedance procedure for measurement of gastrointestinal motility. J Gastrointest Motil 1991;3:151-62.

10 Sifrim D, Holloway R, Silny J, et al. Acid, nonacid, and gas reflux in patients with gastro-oesophageal reflux disease during ambulatory 24 -hour $\mathrm{pH}$ impedance recordings. Gastroenterology 2001;120:1588-98.

11 Shay S, Tutuian R, Sifrim D, et al. Twenty-four hour ambulatory simultaneous impedance and $\mathrm{pH}$ monitoring: a multicenter report of normal values from 60 healthy volunteers. Am J Gastroenterol 2004;99:1037-43.

12 Sifrim D, Castell D, Dent J, et al. Gastro-oesophageal reflux monitoring: review and consensus report on detection and definitions of acid, non-acid, and gas reflux. Gut 2004;53:1024-31.

13 Avidan B, Sonnenberg A, Schnell TG, et al. Temporal associations between coughing or wheezing and acid reflux in asthmatics. Gut $2001 ; 49: 767-72$

14 Harding SM, Guzzo MR, Richter JE. 24-h esophageal pH testing in asthmatics: respiratory symptom correlation with esophageal acid events. Chest 1999; 115:654-9.

15 Schnatz PF, Castell JA, Castell DO. Pulmonary symptoms associated with gastro-oesophageal reflux: use of ambulatory $\mathrm{pH}$ monitoring to diagnose and to direct therapy. Am J Gastroenterol 1996;91:1715-18.

16 Paterson WG, Murat BW. Combined ambulatory esophageal manometry and dual-probe $\mathrm{pH}$-metry in evaluation of patients with chronic unexplained cough. Dig Dis Sci 1994;39:1117-25.

17 Wunderlich AW, Murray JA. Temporal correlation between chronic cough and gastro-oesophageal reflux disease. Dig Dis Sci 2003;48:1050-6.

18 Lam HG, Breumelhof R, Roelofs JM, et al. What is the optimal time window in symptom analysis of 24-hour esophageal pressure and $\mathrm{pH}$ data? Dig Dis Sci 1994;39:402-9.

19 Weusten BL, Roelofs JM, Akkermans LM, et al. The symptom-association probability: an improved method for symptom analysis of 24-hour esophageal pH data. Gastroenterology 1994;107:1741-5.

20 Ing AJ, Ngu MC, Breslin AB. Pathogenesis of chronic persistent cough associated with gastro-oesophageal reflux. Am J Respir Crit Care Med 1994; 149:160-7 
21 Prakash $\mathrm{Ch} \mathrm{CR}$. Extended $\mathrm{pH}$ monitoring with the Bravo capsule increases diagnostic yield in chest pain patients. Gastroenterology 2004;126:A321

22 Irwin RS, Corrao WM, Pratter MR. Chronic persistent cough in the adult: the spectrum and frequency of causes and successful outcome of specific therapy. Am Rev Respir Dis 1981;123:413-17.

23 Smyrnios NA, Irwin RS, Curley FJ. Chronic cough with a history of excessive sputum production. The spectrum and frequency of causes, key components of the diagnostic evaluation, and outcome of specific therapy. Chest 1995; 108:991-7.

24 Ing AJ, Ngu MC, Breslin AB. Chronic persistent cough and gastrooesophageal reflux. Thorax 1991;46:479-83.

25 Kiljander TO, Salomaa ER, Hietanen EK, et al. Chronic cough and gastrooesophageal reflux: a double-blind placebo-controlled study with omeprazole. Eur Respir J 2000;16:633-8.

26 Irwin RS, Zawacki JK, Wilson MM, et al. Chronic cough due to gastrooesophageal reflux disease: failure to resolve despite total/near-total elimination of esophageal acid. Chest 2002;121:1132-40.

27 Allen CJ, Anvari M. Does laparoscopic fundoplication provide long-term control of gastro-oesophageal reflux related cough? Surg Endosc 2004:18:633-7.

28 Zerbib F, Guisset O, Lamouliatte H, et al. Effects of bronchial obstruction on lower esophageal sphincter motility and gastro-oesophageal reflux in patients with asthma. Am J Respir Crit Care Med 2002;166:1206-11.

29 Mello CJ, Irwin RS, Curley FJ. Predictive values of the character, timing, and complications of chronic cough in diagnosing its cause. Arch Intern Med 1996; 156:997-1003.
30 Irwin RS, French CL, Curley FJ, et al. Chronic cough due to gastrooesophageal reflux. Clinical, diagnostic, and pathogenetic aspects. Chest 1993; 104:1511-17.

31 Patti MG, Debas HT, Pellegrini CA. Esophageal manometry and 24-hour pH monitoring in the diagnosis of pulmonary aspiration secondary to gastrooesophageal reflux. Am J Surg 1992;163:401-6.

32 Eubanks TR, Omelanczuk P, Hillel A, et al. Pharyngeal pH measurements in patients with respiratory symptoms before and during proton pump inhibitor therapy. Am J Surg 2001;181:466-70.

33 Mittal RK. Measuring esophageal distention by high-frequency intraluminal ultrasound probe. Am J Med 2003;115(suppl 3A):130-6S.

34 Tipnis TA, Mittal YR, Liu J, et al. Gastro-oesophageal reflux induced distension of esophagus: comparison between symptomatic and asymptomatic reflux episodes. Gastroenterology 2004;126:A-111.

35 Irwin RS, Madison JM. Diagnosis and treatment of chronic cough due to gastro-esophageal reflux disease and postnasal drip syndrome. Pulm Pharmacol Ther 2002; 15:261-6.

36 Sifrim D, Holloway R, Silny J, et al. Composition of the postprandial refluxate in patients with gastro-oesophageal reflux disease. Am J Gastroenterol 2001;96:647-55.

37 Vela MF, Tutuian R, Katz PO, et al. Baclofen decreases acid and non-acid post-prandial gastro-oesophageal reflux measured by combined multichannel intraluminal impedance and $\mathrm{pH}$. Aliment Pharmacol Ther 2003;17:243-51.

38 Koek GH, Sifrim D, Lerut T, et al. Effect of the GABA(B) agonist baclofen in patients with symptoms and duodeno-gastro-oesophageal reflux refractory to proton pump inhibitors. Gut 2002;52:1397-402.

\section{EDITOR'S QUIZ: GI SNAPSHOT}

\section{Clue to a more serious diagnosis}

\section{Clinical presentation}

An 82 year old non-diabetic man on haemodialysis three times a week presented with a two day history of epigastric pain with nausea, fatigue, and a cold painful left lower extremity. He complained of chronic claudication after an ambulatory distance of $50 \mathrm{~m}$ and a two month history of postprandial abdominal discomfort. Physical examination revealed isolated epigastric tenderness, absent left femoral pulse, and a cold insensitive left lower extremity. Rectal examination was normal. Leucocytosis of $34000 / \mathrm{mm}^{3}$ (80\% polymorphonuclear) was the only striking biological abnormality. Immediate enhanced computed tomography scan of the abdomen (fig l) was obtained and upper endoscopy was performed (fig 2).

\section{Question}

How can these examinations help in integrating the whole clinical syndrome?

See page 487 for answer

This case is submitted by:

B Abboud, W Mchayleh Department of General Surgery, Hotel Dieu de France Hospital, Faculty of Medicine, Saint-Joseph University, Beirut, Lebanon G Sleilaty

Department of Cardiovascular and Thoracic surgery, Hotel Dieu de France Hospital, Faculty of Medicine, Saint-Joseph University, Beirut, Lebanon C Yaghi

Department of Gastroenterology, Hotel Dieu de France Hospital, Faculty of Medicine, Saint-Joseph University, Beirut, Lebanon

Correspondence to: $\operatorname{Dr}$ B Abboud, Department of General Surgery, Hotel Dieu de France Hospital, Alfred Naccache Street, Beirut, Lebanon dbabboud@yahoo.fr

doi: 10.1136/gut.2004.049494
Robin Spiller, Editor

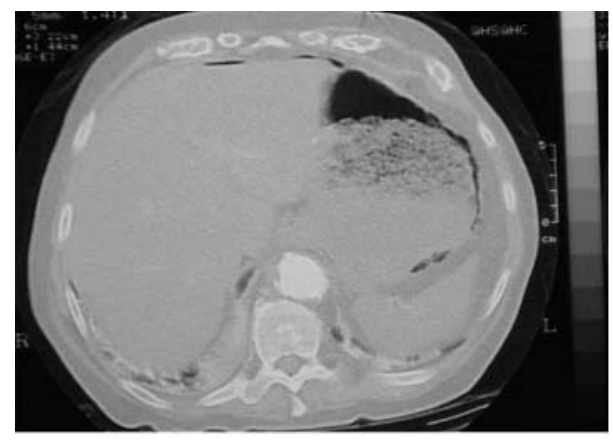

Figure 1 Enhanced computed tomography scan of the abdomen.

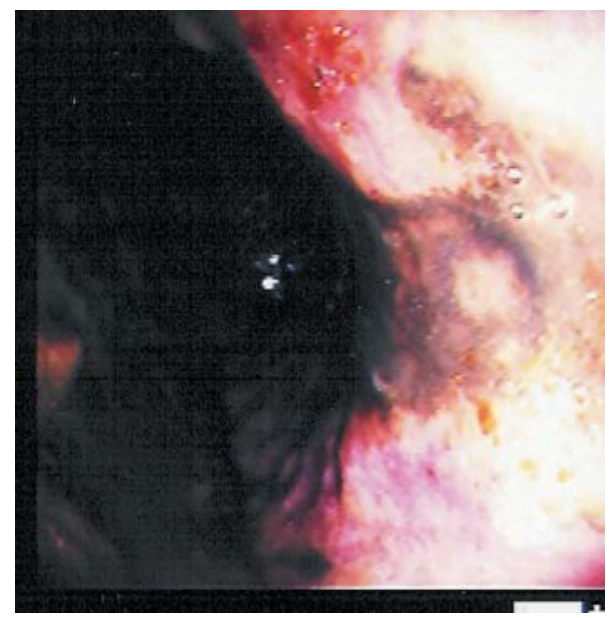

Figure 2 Upper endoscopy. 